\title{
El derecho de libertad en eduardo garcía MÁYNEZ
}

\section{JESÚS AQUILINO FERNÁNDEZ SUÁREZ1}

REsumen: En este trabajo, se hace un análisis del derecho de libertad en el pensamiento de Eduardo García Máynez. La distinción entre la libertad como derecho y como poder, la definición positiva del derecho de libertad y su conexión y relación con otros conceptos afines. Una vez delimitado el derecho de libertad, se aborda el debate entre Carlos Cossio y Eduardo García Máynez a propósito del mismo, y por último se realiza un balance de los aspectos más significativos de esa discusión.

Palabras clave: García Máynez, derecho de libertad, libertad jurídica, libertad como derecho, libertad como poder, facultas optandi, Carlos Cossio.

ABSTRACT: In this work, is made an analysis of the right to freedom in the thought of Eduardo García Máynez. The distinction between freedom as a right and as power, the positive definition of the right to freedom and their connection and relationship with other related concepts. Once defined the right of freedom, deals with the debate between Carlos Cossio and Eduardo García Máynez with regard to the same, and finally is carried out an assessment of the most significant aspects of this discussion.

Keywords: García Máynez, right to freedom as law, legal freedom, freedom as a right, freedom as power, facultas optandi, Carlos Cossio.

SUMARIO: I. Introducción. Libertad como derecho y como poder; II. La libertad jurídica y el derecho de libertad; III. El debate entre Máynez y Cossio; IV. Balance.

1 Profesor Titular de Filosofía del Derecho de la Universidad de Oviedo (España), <aquilino@uniovi.es>. 


\section{INTRODUCCIÓN. LIBERTAD COMO DERECHO Y COMO PODER}

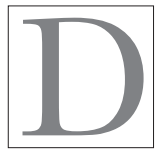

urante los años 1938 a 1961 el derecho de libertad o también denominado la libertad jurídica, fue objeto de especial atención por parte del profesor Eduardo García Máynez, así como la diferenciación entre la libertad jurídica y la libertad natural o libertad como poder (o sea, la libertad de la voluntad).

Prueba del interés que despertó este tópico en Máynez son, los múltiples ensayos que le dedicó, ${ }^{2}$ la polémica mantenida con

2 El primer trabajo que conocemos, sobre este tema, se remonta a 1938: "Libertad jurídica y libertad natural", en Revista de Derecho y Ciencias Sociales (R.D.C.S.), $1^{\mathrm{a}}$ época, $\mathrm{n}^{\circ} 1$, febrero, México, 1938, pp. 20-21; con posterioridad, podemos mencionar los siguientes: "La libertad como derecho", en Revista de la Escuela $\mathrm{Na}$ cional de furisprudencia; t. I, n 3, julio-agosto, México, 1939, pp. 299-310; en el libro Introducción al estudio del Derecho, México, Porrúa, 1984, dedica a la libertad jurídica las páginas 215-226; Libertad, como derecho y como poder. Definición positiva y ensayo de justificación filosófica del derecho de libertad, México. C.I.A. General Editora, 1941, 87 pp.; "Una discusión sobre el concepto jurídico de libertad", en FUS Revista de Derecho y Ciencias Sociales, t.VIII, nº 47, junio, México, 1942, pp. 351-385, en ese mismo año, este artículo vio la luz como publicación de la Imprenta Universitaria, México, 38 pp.; "Libertad como derecho y como poder", Philosophy and Phenomenological Research, V.IV, no 2, diciembre, 1943-44, New York, pp. 146-155 ( la traducción inglesa de este artículo: "Liberty as Right and Liberty as Power", realizada por Cornelius Krusé, se incluye en el mismo número en las páginas 155-164); "La Axiomática jurídica y el derecho de libertad", en Revista de la Universidad de San Carlos, $\mathrm{n}^{\circ}$ 2, enero-marzo, 1946, Guatemala, pp. 204-219, este ensayo constituye el primer intento de axiomatización del derecho de Máynez, y resulta significativa la circunstancia de realizar dicha tarea en conexión con un tema como el de la libertad jurídica. Dicho trabajo se recoge posteriormente como apéndice I (pp. 83-99) en la obra Los principios de la Ontología Formal del Derecho y su expresión simbólica, México, Imprenta Universitaria, 1953, 174 pp.; "Liberty as Richt and as Power", Latin-American Legal Philosophy, Cambridge, Massachusetts, Harvard University Press (20 th. Century Legal Philosophy Series, V.III), 1948, pp. 513-547; en el libro Introducción a la lógica jurídica, México, Fondo de Cultura Económica, 1951, 257 pp., dedica al derecho de libertad las páginas 201-226; "Libertad como derecho y como poder", en apéndice II (pp. 101-162) del libro Los principios de la Ontología Formal Del derecho y su expresión simbólica, cit., se trata de una nueva publicación del trabajo del mismo título publicado, según Máynez, en 1939, y que está agotado; 
el profesor argentino Carlos Cossio ${ }^{3}$ y la infinidad de comentarios realizados por autores diversos sobre esta cuestión en su "obra". ${ }^{4}$

Aquí, y en este momento, simplemente deseo apuntar los aspectos más significativos y novedosos de dicha aportación, así como algunas consideraciones críticas sobre la discusión mantenida con el Prof. argentino Carlos Cossio.

"Libertad jurídica", Enciclopedia furídica Omeba, t. XVIII, Buenos Aires, 1961, pp. 597-601; en Filosofía del Derecho, México, Porrúa, 1977, dedica las páginas 389-398 al derecho de libertad.

${ }^{3} \mathrm{El}$ profesor argentino en el libro La plenitud del ordenamiento furídico, Buenos Aires, Losada,1947, dedica las páginas 92-114 a comentar y criticar el derecho de libertad de Máynez. A la anterior crítica responde Máynez con: Una Discusión Sobre el Concepto Furídico de Libertad (Respuesta a Carlos Cossio), México, Imprenta Universitaria, 1942, 38 pp. Este trabajo fue publicado también en $\mathcal{J} U S$ Revista de Derecho y Ciencias Sociales, t. VIII, no 47, junio, 1942, México, pp. 351-385 (citaremos por aquí, por ser más fácil su localización).

4 Véase, simplemente a modo de ejemplo, los comentarios realizados por: Luis Recasens Siches, "Estudios de Filosofía del Derecho", incluidos en la trad. castellana de la Filosofía del Derecho de Giorgio del Vecchio, t.II, México, Unión Tipográfica Editorial Hispano Americana, 1946, pp. 596-602, o en su Panorama del Pensamiento furídico en el siglo XX, México, Porrúa, 1963, pp. 362-363; Rafael Rojina Villegas, Introducción y Teoría Fundamental del Derecho y del Estado, t.I, México, Talleres de El Nacional, 1944, pp. 662-664; Abelardo Rojas Roldán, "La concepción multirrelacional del derecho de Eduardo García Máynez", en Estudios de Filosofía del Derecho. Homenaje al Doctor Eduardo García Máynez, México, Facultad de Derecho, UNAM, 1973, pp. 305-324 (en concreto pp. 319-322); Miguel Villoro Toranzo, Introducción al estudio del derecho, México, Porrúa, 1974, pp. 455-456; Martín Diego Farrel, Cuestiones de Filosofia y Derecho, Buenos Aires, Cooperadora de Derecho y Ciencias Sociales, 1977, pp. 35-45 y en especial pp. 39-40; Ernest Hocking Willian, "Comments on Professor Máynez paper on <Liberty as Richt and as Power>", Philosophy and Phenomenological Research, V IV, $\mathrm{n}^{\circ}$ 2, diciembre, New York, 1943-44, pp. 165-166; Leopoldo Zea, La Filosofía en México, t. II, México, Biblioteca Mínima Mexicana, Libro-Mex. Editores, 1955, dedicado a Máynez pp. 207-217, y a su derecho de libertad, pp. 214-216; Josef L. Kunt, La filosofía del derecho latinoamericana en el siglo XX, Buenos Aires, Losada, 1951, de dedicado a Máynez pp. 181-191, y a su derecho de libertad pp. 185-186; Rafael Rojina Villegas, Teoría jurídica de la conducta, México, Ediciones Botas, 1947, pp. 65-81. 
Es importante adelantar que la libertad que nos interesa, es la libertad en relación con el derecho, la libertad jurídica, o como también la denomina Máynez, el derecho de libertad. La libertad en sentido metafísico o filosófico nos reenvía a problemas y campos muy diversos, en tanto que presupuesto necesario para dar sentido a las acciones humanas y sin la cual pierde todo interés cualquier filosofía práctica del actuar humano.

Dada la gran equivocidad del término "libertad", la primera cuestión que aborda García Máynez es la de distinguir la libertad como atributo de la voluntad del hombre, de la libertad como derecho. Mientas que la primera es considerada como poder, o facultad natural, en cuanto aptitud de obrar por sí, o en terminología kantiana, una causalidad cuyo primer momento es solo causa, no efecto de otra causa. La segunda, la jurídica, no es ni poder, ni capacidad derivada de la naturaleza, sino -según Máynez-facultad derivada de una norma, derecho, autorización, lo que en terminología alemana se denomina "dürfen". 5

Para percibir con mayor claridad esa diferenciación, nada mejor que señalar las relaciones entre ambos tipos de libertad. La libertad jurídica y todos los derechos subjetivos son -según Máynez- posibilidades de acción o de omisión que, al realizarse, necesariamente ostentan el signo de la licitud. Pero estas posibilidades no se actualizan por sí mismas, sino que dicha realización depende de la voluntad del titular. De tal manera que la libertad como derecho, implica el de la libertad como poder o, lo que es igual, la manifestación exterior del albedrio de cada persona. ${ }^{6}$ Mientras la libertad como derecho sólo se manifiesta en los actos jurídicos potestativos, la libertad como poder se manifiesta, además de en los anteriores, en los ordenados y en los prohibidos. Esto es, la manifestación del libre

5 Ver, "La libertad como derecho", cit., p. 300; Introducción al estudio del derecho, cit., p. 216.

6 Cfr., Filosofia del Derecho, cit., p. 394; Introducción a la lógica jurídica, cit. p. 217; "Libertad, como derecho y como poder", cit., p. 149. 
albedrío desde la óptica jurídica puede consistir: "a) en el ejercicio o no ejercicio de un derecho subjetivo; b) en la comisión o la omisión de actos prohibidos; c) en el cumplimiento o incumplimiento de un mandato". ${ }^{7}$ Otra manera de clasificar las formas de actividad de un sujeto en relación con el derecho, es la que podemos ver en el siguiente cuadro sinóptico elaborado por Máynez, y que en líneas generales coincide con la clasificación anterior, aunque se observan algunas diferencias, veamos: ${ }^{8}$

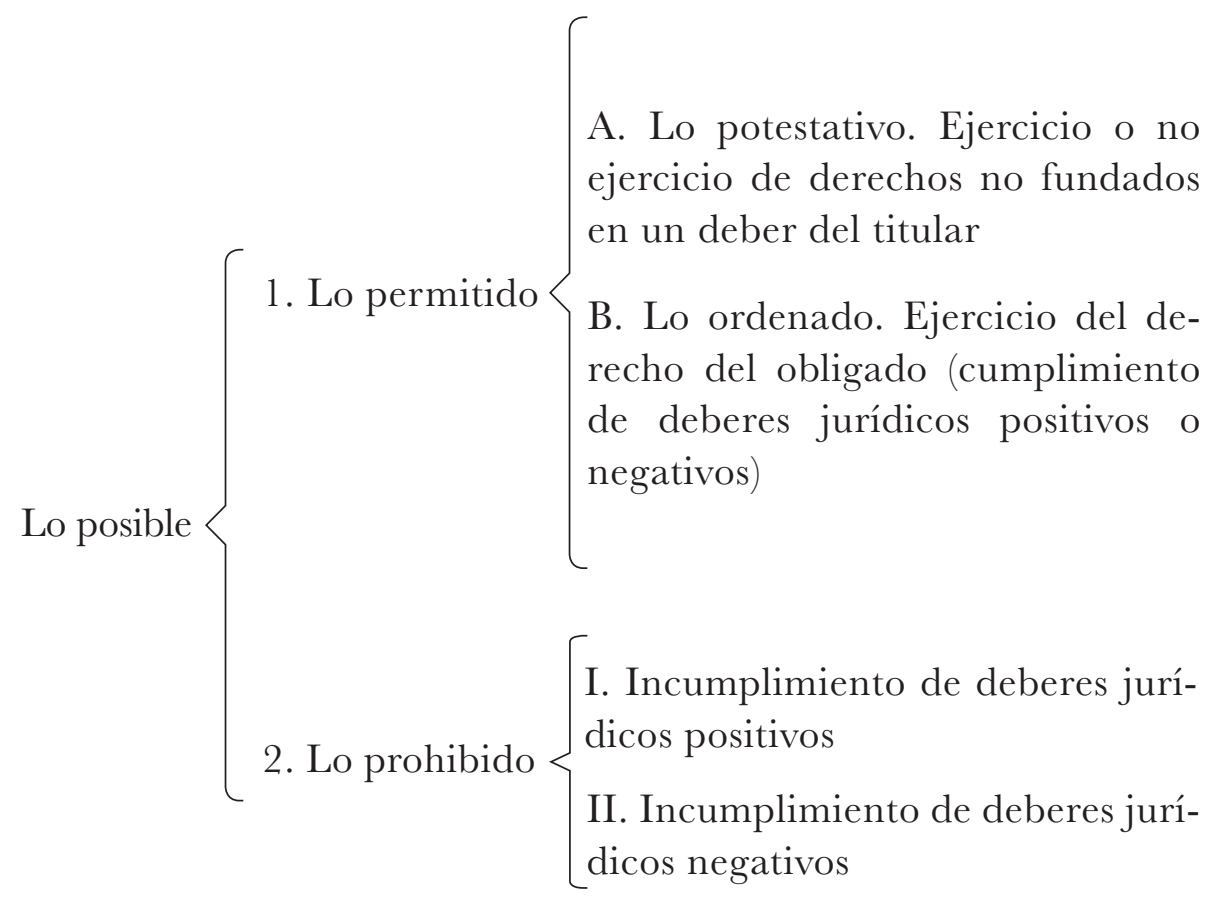

Todas las formas de actividad anteriores pueden considerarse como manifestaciones de la libertad del querer o como poder; en tanto que al ámbito de la conducta jurídicamente libre únicamente pertenecen las designadas en el grupo A. Conviene destacar lo

7 "Libertad, como derecho y como poder", cit., p. 150.

${ }^{8}$ Ver, Introducción a la lógica jurídica, cit., p. 150. 
anterior, pues es esencial en la noción de libertad como derecho en Máynez, y en cambio iusfilósofos como Recasens Siches lo interpretan erróneamente - al menos eso pensamos- de forma que incluyen también el ámbito del apartado B. ${ }^{9}$

En conclusión, y en palabras del propio Máynez, "mientras la libertad, como derecho, se halla exclusivamente referida a la ejecución o la omisión de actos no ordenados ni prohibidos, la libertad como poder se manifiesta tanto en la ejecución o en la omisión de actos no ordenados ni prohibidos, cuando en la ejecución o en la omisión de actos ordenados y de actos ilícitos"10 (el subrayado es nuestro).

\section{LA LIBERTAD JURÍdICA Y EL DERECHO DE LIBERTAD}

A la hora de precisar la noción de libertad jurídica, dos son los autores a los que presta especial atención García Máynez, al procesalista italiano Hugo Rocco y al iusfilósofo Hans Kelsen.

Frente a la tesis de Hugo Rocco de que el derecho de libertad es una suma de facultades agendi, ya que todo ciudadano se encuentra autorizado para hacer lo que no está prohibido y omitir lo que no

9 Ver, Luis Recasens Siches, Panorama del Pensamiento Furídico en el siglo XX, cit., p. 363, donde comentando el concepto de libertad jurídica de Máynez dice: "Como la norma que señala un deber no siempre indica - ni muchas veces puede hacerlo - los medios para llevar a un cumplimiento aquél, en tales casos el sujeto ha de elegir y por tanto tiene el derecho de emplear cualquiera de los posibles lícitos. Esta facultad de opción es precisamente la libertad jurídica" (el subrayado es nuestro); y en el mismo sentido véase: Luis Recasens Siches, "Estudios de Filosofía del Derecho", en Filosofia del Derecho de Giorgio del Vecchio, cit., p. 599. Tal interpretación de la libertad jurídica como el cumplimiento alternativo u opcional del deber no puede confundirse o identificarse con la libertad jurídica que, según Máynez, sólo se manifiesta en el ámbito de los derechos subjetivos independientes como posibilidad de su ejercicio o no ejercicio. Una cosa es la facultas optandi de segundo grado, propia de la libertad jurídica, y otra la facultas optandi de ejercicio obligatorio, del tipo, por ejemplo, de las obligaciones alternativas.

10 Eduardo García Máynez, Filosofía del Derecho, cit., pp. 394-395; Introducción a la lógica jurídica, cit., pp. 218; "Libertad Jurídica", cit., p. 601. 
está mandado, Máynez presenta un par de objeciones: $1^{\mathrm{a}}$.-La libertad jurídica no comprende sólo un conjunto de facultades agendi, sino qué como el resto de los derechos absolutos, ofrece un doble aspecto, en su cara interna es un haz de facultades agendi; y en su aspecto externo constituye una serie de facultades exigendi. $2^{a}$.- La libertad jurídica no sólo puede definirse negativamente, estableciendo sus límites; sino que debe establecerse una definición positiva en la que se nos indique su esencia. ${ }^{11}$

De Kelsen, destaca la teoría que considera a la libertad no como un derecho, sino como un concepto que duplica de modo innecesario la noción de deber jurídico. Crítica que no sólo afecta a la libertad jurídica, sino a todos los derechos subjetivos, pues tal como señala Kelsen: "Si bien se mira, el «poder» (en sentido de «estar autorizado») es deber ser, es norma jurídica; el derecho subjetivo es Derecho objetivo, y sólo en cuanto tal tiene existencia en la esfera del Derecho". ${ }^{2}$ Máynez, reconoce el valor de la tesis de la relación o carácter complementario que existe entre derechos y deberes, o si se prefiere la expresión, que las facultades son correlativas de un deber de respeto; pero discrepa en casi todo lo demás, y en especial en la identificación entre derecho objetivo y derecho subjetivo, pues ello equivale a confundir las nociones de norma y facultad. El derecho subjetivo o facultad es una posibilidad de acción de acuerdo a un precepto; mientras que la regla normativa es, el fundamento de tal facultad. La circunstancia de que uno derive del otro, no demuestra que sean una misma cosa. ${ }^{13}$

Como ya hemos apuntado, el propósito principal de nuestro autor es el de superar la definición negativa o tradicional de la libertad

11 Cfr., "Libertad, como derecho y como poder", cit., pp. 128-129. Los comentarios sobre Hugo Rocco, están tomados de su libro L'autoritá della cosa giudicata e $i$ suoi limiti soggetivi, Roma, Athenaeum, 1917.

12 Hans Kelsen, Teoría General del Estado, (trad. Luis Legaz Lacambra) Barcelona, Edit. Labor, 1934, p. 73.

13 Cfr., "Libertad, como derecho y como poder", cit., pp. 133-136. 
jurídica. De acuerdo con esta orientación tradicional, "la libertad, en sentido jurídico, es la facultad de ejecutar o de omitir, al arbitrio del sujeto, todo acto no ordenado y no prohibido por la ley". ${ }^{14}$ Definición que se basa en la división de los posibles comportamientos humanos en relación con el derecho en tres categorías de actos: ordenados, prohibidos y permitidos (o no ordenados ni prohibidos). Gráficamente podríamos representarlo así:

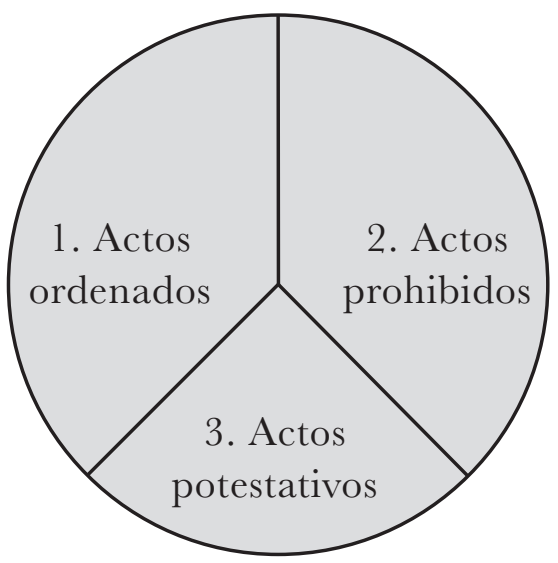

El primer sector lo comprende los deberes positivos del sujeto (obligaciones de hacer o de dar); el segundo, los deberes negativos (obligaciones de no hacer); el tercero, sus derechos. Y de acuerdo con la teoría tradicional la libertad jurídica se manifiesta en la realización o no de los actos del tercer sector.

Tal clasificación es inadecuada para García Máynez, entre otras razones, por las siguientes: $1^{\mathrm{a}}$ el primer sector, el de lo mandado $\mathrm{u}$ ordenado, no sólo se refiere a "acciones", pues muchos deberes son omisiones (falta de acción); $2^{a}$ el segundo sector, el de lo prohibido,

14 Ver, Filosofía del Derecho, cit., p. 389; Cfr., Introducción a la lógica jurídica, cit., p. 201 ("el derecho de ejecutar u omitir aquellos actos que no están ordenados ni prohibidos); Cfr., "Libertad, como derecho y como poder", cit., p. 109 ("la facultad de hacer u omitir aquello que no está ordenado ni prohibido"); Cfr., Introducción al estudio del derecho, cit., p. 219; Cfr., "La libertad como Derecho", cit., p. 302. 
no sólo se debe referir a no hacer, pues en muchos casos lo que se prohíbe es precisamente una omisión (se pueden prohibir acciones u omisiones); $3^{\mathrm{a}}$ el tercero, si bien es el referido a los derechos, no es exclusivo, ya que en el primero también existen los llamados derechos de cumplir con el propio deber.

En la anterior clasificación, el sector de los procederes libres queda determinado por exclusión, se integra por los comportamientos que la ley no prohíbe ni manda. Lo cual hizo pensar a algunos autores que ese ámbito debe ser considerado como un espacio jurídicamente vacío, o como dice Kelsen, existe una relación entre el derecho y dichos comportamientos puramente negativa. ${ }^{15}$ Según Máynez, afirmar que los actos de esta clase no están jurídicamente regulados, es un error que se olvida de lo siguiente: “1. Que el sector de lo potestativo no está exclusivamente integrado por esas formas de conducta que no son objeto de una regulación expresa; 2. Que la circunstancia de que una conducta no sea materia de regulación no la priva de su carácter potestativo ( en el supuesto claro está, de que no se encuentre ordenada ni prohibida)". ${ }^{16}$ En relación con la primera objeción, parece claro que las normas del derecho pueden conceder expresamente a una persona la facultad de realizar u omitir determinados actos. En apoyo de la segunda objeción, Máynez señala lo siguiente: "aun cuando ninguna norma confiera expresamente a un acto carácter potestativo, el acto tiene tal carácter, porque el orden jurídico concede en forma presunta la facultad de hacer u omitir lo que sus normas no ordenan ni vedan". ${ }^{17}$

15 Introducción al estudio del derecho, cit., p. 219; Introducción a la lógica jurídica, cit., p. 202; Filosofía del Derecho, cit., p. 390.

16 Ídem, la consideración final resulta difícil de entender, esto es, como es posible que una conducta que no sea materia de regulación, pueda estar ordenada o prohibida.

17 Tal afirmación resulta problemática y poco clarificadora sobre la situación o el estatus de las conductas que el derecho no menciona expresamente y sobre la posibilidad de la existencia de algún postulado de "clausura" del sistema jurídico. Sobre esto véase: Martín Diego Farrel, Cuestiones de Filosofía y Derecho, cit., pp. 39- 
Afirmación que resulta de difícil encaje con esta otra del mismo autor: "para sostener que una conducta está jurídicamente permitida no basta la comprobación de que no está expresamente prohibida, ya que... la prohibición puede estar implícita”. ${ }^{18}$

La clasificación tripartita de las formas de conducta jurídicamente reguladas (obligatorias, prohibidas y permitidas) realizada por la doctrina tradicional cuando delimita el derecho de libertad, es inadecuada, según García Máynez, dado que el ámbito de lo permitido no se identifica con el de los actos libres o potestativos. Lo permitido es más amplio, pues no sólo se tiene la facultad de hacer lo que el derecho objetivo no manda ni prohíbe, sino también la de realizar lo que ordena. Este ámbito de lo permitido se corresponde con el de lo lícito; y el de lo prohibido con lo ilícito. Pero la actividad lícita rebasa el ámbito de la actividad jurídicamente libre, ya que en ella debemos distinguir lo lícito obligatorio y lo lícito potestativo. De ahí la siguiente propuesta de clasificación de las actividades jurídicamente reguladas en: I. Son lícitas: a) la ejecución

40, donde señala que "de acuerdo con esta concepción (la de Máynez), pareciera ser que, para que pueda calificarse a una conducta de «jurídicamente libre», el derecho tiene que mencionarla, declarándola facultativa. De lo contrario, la conducta sería «libre» (en el sentido de admitir una decisión volitiva contraria), pero no «jurídicamente libre»”. Interpretación que le resulta problemática a Farrel, por lo que entiende que Máynez después de ser consciente del carácter analítico de sus principios, "propuso completar su formulación de esta manera: lo que no está expresamente prohibido, debe considerarse como implícitamente permitido". Por nuestra parte, pensamos que dicha formulación no se corresponde con la realizada por Máynez, y que el contexto de la misma era la regla técnica usada por Kelsen en relación con lo que cada sistema en concreto determine positivamente. Véase sobre esto: Eduardo García Máynez, "Los principios generales del derecho y la distinción entre principios jurídicos normativos y no normativos", Scritti Guirídici in Memoria di Piero Calamandrei, V.1, Padova, Cedam, 1958, pp. 227-242 (recopilado en: Ensayos filosófico-jurídicos 1934-1979, México, Textos Universitarios, UNAM, Facultad de Derecho, 1984, 413 pp. Se cita por aquí, en pp. 170.171).

18 "Los principios generales del derecho y la distinción entre principios jurídicos normativos y no normativos", en Ensayos filosófico-jurídicos 1934-1979, cit., p. 172. 
de los actos ordenados; b) la omisión de los actos prohibidos; c) la ejecución o la omisión de los que no están ordenados ni prohibidos. II. Son ilícitas: a) la omisión de los actos ordenados; b) la ejecución de los prohibidos. ${ }^{19}$

En el ensayo "Libertad jurídica", nuestro autor, piensa que la clasificación tripartita, debe reducirse desde el punto de vista lógico, a la división de los procederes regulados por el derecho en conductas de ejercicio potestativo y de ejecución no potestativa. Y estos últimos, a su vez, se subdividen en jurídicamente ordenados y jurídicamente prohibidos. ${ }^{20}$ Este parece ser el criterio de división más acorde con la idea de libertad jurídica de Máynez, el de diferenciar los derechos en de ejercicio potestativo y de ejercicio obligatorio. ${ }^{21}$ Solamente en los primeros es posible que se manifieste la libertad en sentido jurídico; y tomando esto como base es posible definir la libertad jurídica en sentido positivo. Quedando relegada la definición negativa, que es la que determina el ámbito de la liberad jurídica por exclusión de los procederes que no son libres, para indicar los límites, pero no el contenido o la esencia de dicho derecho. ${ }^{22}$ De donde: "Libertad jurídica, en sentido positivo, es la facultad que toda persona tiene de optar entre el ejercicio y el no ejercicio de sus derechos subjetivos, cuando el contenido de los mismos no se agota en la posibilidad

19 Cfr., Introducción al estudio del derecho, cit. p. 221; Introducción a la lógica jurídica, cit., p. 206; "Libertad, como derecho y como poder", cit., p. 110.

20 "Libertad jurídica", cit., pp. 597-598.

21 Criterio adoptado también en Filosofia del Derecho, cit., p. 391.

22 En sus propias palabras: "Cuando se dice que libertad es el derecho de optar entre la ejecución y la omisión de los comportamientos que no están prohibidos ni ordenados, ese derecho es definido negativamente, ya que el ámbito de la conducta potestativa se determina por exclusión de los procederes que las normas del derecho objetivo ordenan o prohíben. Lo jurídicamente libre resulta así lo jurídicamente no ordenado ni prohibido, lo cual revela que la definición negativa, más que indicarnos lo que la libertad es, únicamente dice lo que no es o, en otras palabras, señala sus límites, pero no su esencia" ("Libertad jurídica", cit., p. 598). 
normativa de cumplir un deber propio". ${ }^{23}$ La libertad en sentido jurídico, hace referencia al ejercicio o no ejercicio de los derechos subjetivos, por lo que se la debe considerar más que como otro derecho al lado de los ya conocidos, como una "forma categorial de manifestación de todo derecho subjetivo, absoluto o relativo, privado o público". ${ }^{24} \mathrm{No}$ debemos perder de vista la distinción existente entre los derechos y el ejercicio de los mismos. Mientras los derechos son posibilidades normativas o facultades de obrar en distintos sentidos; el ejercicio de los derechos es un hecho, que consiste en la realización de lo que la norma autoriza.

El derecho de libertad, como su propio nombre indica, es un derecho que consiste en la facultad de optar entre el ejercicio o no ejercicio de otro derecho en el que se funda. Y en este sentido es clarificador el responder a dos cuestiones: a) ¿en qué consiste ese "fundarse" o "fundamentarse" ?; b) ¿qué derechos pueden servir de fundamento al derecho de libertad? Ambos interrogantes están ligados o entrelazados, pero antes de responder a los mismos conviene hacer ciertas precisiones de orden terminológico. García Máynez a

23 Ver, Filosofía del Derecho, p. 391; Cfr., Introducción al estudio del derecho, p. 222; Cfr., Introducción a la lógica jurídica, p. 208; "Libertad jurídica", p. 600; "La libertad como Derecho", pp. 307-308; "Libertad, como derecho y como poder", p. 111; sobre esta definición positiva y sus características, véase también: "La Axiomática jurídica y el derecho de libertad", en Los principios de la Ontología Formal del Derecho y su expresión simbólica, cit., axioma noveno, pp. 97-98, donde se señala que de la definición positiva se infiere: 1. Que el de libertad es una facultad fundada en otro derecho. 2. Que se refiere a el ejercicio o no ejercicio de la facultad fundante. 3. Que el del obligado no puede servir de fundamento a un derecho de libertad. 4. Que todos los derechos que no se agotan en la facultad de cumplir un deber propio son de primer grado y, por ende, susceptibles de servir de fundamento a la facultas optandi. 5. Que la libertad jurídica es un derecho de $2^{\circ}$ grado. 6. Que los tradicionalmente llamados de libertad, son de primer grado. 7. Que estos últimos, en cuanto derechos autónomos, pueden ejercitarse o no ejercitarse, por lo cual resultan fundantes del verdadero derecho de libertad, que es de segundo grado.

24 "La libertad como Derecho", p. 304; Introducción al estudio del derecho, p. 222; Filosofía del Derecho, p. 391; Introducción a la lógica jurídica, p. 208; “Libertad, como derecho y como poder", p. 112. 
la hora de clasificar los derechos subjetivos, emplea las expresiones: derechos independientes, de ejercicio potestativo y facultades fundantes como sinónimas; y las contrapone a los derechos dependientes, de ejercicio obligatorio (en los casos en que el derecho consistía en el deber de cumplir con la propia obligación) y facultades fundadas. ${ }^{25} \mathrm{El}$ derecho de libertad aparece ligado a todas las facultades independientes, y el nexo entre dicho derecho y las facultades que lo sustentan o fundan, se puede expresar diciendo que estas últimas son de primer grado, en tanto que aquél es de segundo. A los derechos que no se basan ni en un deber, ni en otro derecho, los denomina Máynez independientes o de primer grado; y los que se fundan en un deber o en otro derecho, dependientes o de segundo grado como es el caso del derecho de libertad o el derecho del obligado. En cuanto a las relaciones, entre los derechos dependientes y los deberes o derechos en los que se fundan, se pueden expresar, de acuerdo con nuestro autor, por medio de los siguientes principios universales y apriorísticos: "1. Todo derecho subjetivo no fundado en un deber del titular es fundante de un derecho de libertad. 2. Ningún derecho subjetivo cuyo fundamento sea un deber jurídico, puede ser fundante de otro derecho. 3. Los que se basan en deberes jurídicos son de ejercicio obligatorio. 4. El de libertad es en todo caso de segundo grado". ${ }^{26}$

Entre el ejercicio del derecho de libertad y el ejercicio de la facultad fundante podemos establecer las siguientes relaciones: El ejercicio de la facultad fundante implica al propio tiempo el ejercicio de la facultad fundada, pero en cambio ejercitar el derecho de segundo grado (el de libertad) no implica en todo caso el ejercicio del otro derecho, porque el titular puede optar por no hacer uso del de primer grado.

25 Sobre las facultades fundantes y fundadas véase: Introducción al estudio del Derecho, cit., pp. 207-208.

26 "Libertad jurídica", p. 600. 
El derecho de libertad es una facultas optandi, ya que consiste en la facultad que se concede al titular del derecho independiente de optar entre el ejercicio y el no ejercicio de éste. Y como se trata de un derecho que se ejercita optando, puede manifestarse tanto en el ejercicio como en el no ejercicio. En el primer caso es una facultas agendi, y el deber correlativo consiste en no impedir al titular el ejercicio de la facultad fundante; en el segundo caso (caso de no ejercicio) se manifiesta como facultas omittendi, y el deber correlativo consiste en no exigir al titular que ejercite su derecho, si no quiere ejercitarlo. Lo cual no significa que existan tres derechos de libertad: facultas optandi, facultas agendi y facultas omittendi; sino que la facultas optandi, en que consiste el derecho de libertad, necesariamente debe manifestarse en un hacer o en un omitir. ${ }^{27}$

En el Derecho, caben distintos tipos de facultas optandi, pues no siempre se trata de facultades de segundo grado como es el caso del derecho de libertad. El orden jurídico puede hacer depender de la realización de un supuesto normativo el nacimiento de dos o más facultades a las que puede optar libremente una persona, con exclusión de las restantes. Aquí la facultas optandi, se manifiesta como una facultad de primer grado, en la que, a su vez, se funda la facultas optandi de segundo grado, que consiste en el ejercicio o no ejercicio de la facultad o facultades entre las que puede optar. Como ejemplos de esto, señala Máynez, la solidaridad pasiva, en la que la facultas optandi del acreedor es de primer grado, o el caso del despido indebido, cuando se concede al trabajador la opción de elegir entre el cumplimiento del contrato o la indemnización. ${ }^{28}$ También es posible una facultas optandi de ejercicio obligatorio, o sea fundada en un deber del titular. Con lo que no puede ser fundante

27 Cfr., Introducción al estudio del derecho, p. 222; Introducción a la lógica jurídica, p. 209, donde añade: "la facultad de optar entre hacer y no hacer algo necesariamente implica la licitud de la acción y la omisión".

28 Cfr., Introducción a la lógica jurídica, pp. 211-212; Filosofía del Derecho, pp. 3931-393. 
de un derecho de libertad, ni de segundo grado. Como ejemplo se señalan las obligaciones alternativas, donde el deudor puede elegir entre diversas prestaciones, pero lo que no puede es renunciar a la elección, ya que su derecho de optar se funda en el deber de hacerlo, por lo que dicho derecho es de ejercicio obligatorio. ${ }^{29}$ Tenemos, al menos, tres tipos distintos de facultas optandi con diverso estatus jurídico: 1. De primer grado; 2. De segundo grado (la propia de la libertad jurídica); 3. De ejercicio obligatorio.

Hay tres cuestiones conexas con el derecho de libertad, cuyo análisis nos puede brindar claridad sobre el mismo, en concreto se trata de: la renuncia de los derechos subjetivos, las denominadas libertades públicas y el abuso del derecho. Veamos cada una de ellas.

La regla general es que el titular de un derecho subjetivo independiente pueda renunciar a éste, siempre que no afecte directamente al interés público y no perjudique a terceros. Pero la anterior regla se rompe ya en el caso de los denominados derechos de ejercicio obligatorio, donde la renuncia es jurídicamente imposible (según Máynez), ya que el derecho del obligado se agota en la facultad de cumplir el propio deber. ${ }^{30}$ Pero donde se pueden plantear más problemas es en los derechos independientes o de primer grado que reciben la denominación de derechos irrenunciables, y que no se fundan como en el caso anterior en ningún deber. Aquí es necesario diferenciar el ejercicio o no ejercicio del derecho, de la facultad de renuncia a dicho derecho, pues desde el punto de vista teórico, mientras la renuncia extingue el derecho, su no ejercicio lo deja en pie. Cuando se dice que un derecho es irrenunciable, se quiere poner de manifiesto que su renuncia no produce efectos legales, lo

29 Cfr., Introducción a la lógica jurídica, p.213; Filosofía del Derecho, p.392. Al respecto recuérdese lo señalado en la nota a pie de página número 8, donde Recasens denominaba a esta opción derecho de libertad.

30 Cfr., Introducción a la lógica jurídica, pp.213-214; Filosofía del Derecho, p.392, donde se añade: "Como el derecho de que estamos tratando es de ejercicio obligatorio, la renuncia sería desde el punto de vista jurídico, inexistente". 
cual es así por voluntad de legislador, que desea salvaguardar determinados intereses del facultado aún en su contra. Pero lo anterior no convierte a la facultad, en facultad de ejercicio obligatorio, sino que sigue existiendo la posibilidad de ejercitarlo o no, lo único que se veta es que la renuncia de esa facultad tenga efectos jurídicos. Por eso los llamados derechos irrenunciables, son fundamento del derecho de libertad que permite optar entre su ejercicio o no ejercicio, aquí lo que se niega es el derecho de renuncia. El derecho de renuncia no es de ejercicio obligatorio, por lo que es fundante de un derecho de libertad, que permite a su titular optar entre su ejercicio y no ejercicio. Esta facultad de renuncia - dice Máynez- es, a un tiempo, dos relaciones distintas, fundante y fundada. Frente al derecho renunciable aparece como fundada; frente al de libertad como fundante. "El titular de un derecho cuya renuncia no se prohíbe tiene, pues dos facultas optandi: 1. la que se refiere al ejercicio o no ejercicio de ese derecho; 2. la referida al ejercicio o no ejercicio del de renuncia". ${ }^{31}$

Conviene no confundir el derecho de libertad con las denominadas "libertades públicas", pues el derecho de libertad se manifiesta no sólo en estas "libertades públicas", sino en todos los derechos subjetivos de ejercicio potestativo. Las libertades públicas, tales como la libertad de pensamiento, de tránsito, de asociación, etc., que normalmente vienen recogidas en textos de naturaleza constitucional, son derechos independientes de primer grado, y como tales fundantes del derecho de libertad (que es un derecho de segundo grado). Según Máynez "la única diferencia entre estas manifestaciones de nuestra libertad jurídica y las referidas a otros derechos independientes estriba en que las primeras (libertades públicas) descansan en facultades que gozan de una protección sui generis, ya que, como es sabido, las leyes en que se fundan no pueden ser mo-

31 Introducción a la lógica jurídica, pp.214-216; Filosofía del Derecho, pp.393-394. 
dificadas o derogadas en la misma forma que las ordinarias". ${ }^{32}$ A lo que deberíamos añadir, que tales derechos no sólo tienen especial protección frente a su posible modificación o derogación, sino que suelen gozar, dado el peso valorativo de su contenido material, de vías preferentes para garantizar su efectividad frente a cualquier tipo de violación o limitación de los mismos.

En lo que se refiere a la conocida teoría del "abuso del derecho", en relación con el derecho de libertad y el ejercicio de los derechos, la posición mantenida por nuestro autor, es la del rechazo absoluto de tal planteamiento teórico dado que: "el uso ilegal de un objeto no puede ser considerado como ejercicio de un derecho". En su opinión, es impropio hablar de abuso o uso abusivo de un derecho, ya que nadie puede abusar de las facultades legales, pues por definición estas excluyen cualquier ejercicio antijurídico. Donde el "abuso" empieza el "derecho" termina, no hay abuso de derecho, sino violación de un deber. ${ }^{33}$

Un aspecto, que nuestro autor destaca desde sus primeros trabajos sobre la libertad jurídica es el de la validez de su concepto de derecho de libertad tanto para una concepción positivista o normativista del derecho como para las doctrinas iusnaturalistas o que admiten la existencia de dos órdenes. La razón de tal elasticidad reposa en el hecho de que esa noción se basa en el análisis de las relaciones ontológico-jurídicas que existen, por un lado, entre el derecho subjetivo y el deber jurídico; y por otro, entre los derechos subjetivos y su ejercicio y no ejercicio. Se trata pues de un con-

32 Introducción a la lógica jurídica, p.224; Filosofía del Derecho, p.398; Cfr., "Libertad jurídica", pp.600-601, para mostrar la conexión necesaria existente entre derecho y deber, y entre derecho y ejercicio del mismo, Máynez realiza la siguiente reflexión: "en un orden normativo en que nadie tuviese más derecho que cumplir con su deber, la libertad no existiría"; "y si todos los derechos fuesen de ejercicio libre no habría en realidad régimen jurídico, porque donde nadie está obligado a nada, nadie puede tener derechos subjetivos".

зз Sobre el "abuso del derecho" en Máynez, ver "Libertad, como derecho y como poder", pp.146-148; Introducción a la lógica jurídica, pp.226-230. 
cepto puramente formal y valido para todo orden jurídico. En un sistema positivista o normativista la esfera de libertad jurídica de cada sujeto vendrá determinada por la de los derechos independientes que el legislador le otorgue. Y en un sistema iusnaturalista, cada sujeto tendrá la libertad jurídica de ejercitar o no ejercitar los derechos independientes que el orden de derecho natural le conceda. Máynez es consciente que la aceptación de un dualismo (orden de derecho natural-orden de derecho positivo) puede plantear conflictos entre preceptos de uno y otro orden, lo que traería consigo también conflictos entre las esferas de libertad que cada orden concede a los titulares de derechos independientes. ${ }^{34}$ Pero dicha tensión o conflicto entre lo puesto y los ideales de justicia, es algo visto como necesario y positivo, dado que "el ámbito de las facultades de estas normas (se refiere a las de cada ordenamiento concreto) conceden a las personas jamás coincide, de manera cabal, con el de los derechos que, desde el punto de vista estimativo debieran reconocérsele". ${ }^{35}$ Y añade como colofón: "Cada vez que los hombres o los pueblos obtienen el reconocimiento de un nuevo derecho, concomitantemente aumenta su libertad; cada vez que sus facultades legales son restringidas, su libertad disminuye. Hablando en lenguaje matemático podríamos declarar que esta última es, en todo caso, un función (entendiendo por tal, variable dependiente de otra variable) de los derechos subjetivos independientes". ${ }^{36}$

34 Cfr., "Libertad, como derecho y como poder", pp. 124-126; Introducción al estudio del derecho, 224-226; Introducción a la lógica jurídica, 219-221; Filosofía del Derecho, pp. 395-397.

35 Introducción a la lógica jurídica, p. 222, el subrayado es nuestro, para destacar la tensión que establece entre el derecho positivo y el ámbito axiológico en su concepción de la idea jurídica y su desarrollo dialéctico, al respecto ver: Jesús Aquilino Fernández Suárez, La Filosofia jurídica de Eduardo García Máynez, Oviedo, Servicio de Publicaciones de la Universidad de Oviedo, 1991, pp. 292-296.

36 Introducción al estudio del derecho, p. 226; "Libertad, como derecho y como poder", p. 125; Introducción a la lógica jurídica, pp. 22-223; Filosofía del Derecho, p. 397. 


\section{El debate entre Máynez y Cossio}

Pasemos al análisis de la polémica mantenida entre García Máynez y Carlos Cossio a propósito del derecho de libertad. Discusión muy conocida a mediados del siglo XX y que despertó especial interés entre la iusfilosofía de habla hispana y portuguesa. El debate se inició a raíz del ensayo de Máynez "Libertad, como derecho y como poder", que fue comentado y criticado por Carlos Cossio en su monografía Las lagunas del derecho. ${ }^{37}$ Por su parte, Máynez respondió a dicha crítica en su ensayo "Una discusión sobre el concepto jurídico de Libertad" (Respuesta a Carlos Cossio). ${ }^{38}$ Y a su vez, Carlos Cossio respondió en su obra La Teoría Egológica del derecho y el concepto jurídico de libertad, ${ }^{39}$ donde dedica un apéndice de unas cincuenta páginas a dicha polémica, Máynez ya no respondió a este último trabajo, con lo que la discusión quedó terminada, al menos entre ellos.

Como ya hemos visto las ideas básicas del derecho de libertad de Máynez, comenzaremos señalando, en primer lugar, los comentarios de Cossio; a continuación, la réplica de Máynez y, por último, un balance de dicha discusión.

Cossio inicia sus comentarios con un elogio y valoración muy positiva de la aportación de Máynez al tema del derecho de libertad, con expresiones tales como "éxito concluyente" o "una base firme para aprovechar y una conclusión definitiva a la cual referirse". ${ }^{40} \mathrm{~A}$ continuación, añade que la respuesta que da el profesor mexicano a la pregunta ¿qué es la libertad jurídica? es "muy particular e impro-

37 Recopilado en el libro de mayor extensión de Cossio La plenitud del ordenamiento jurídico, 2a Edición, Buenos Aires, Losada, 1947, pp. 17-135 (por aquí se citará a continuación, los comentarios a Máynez pp. 92-114).

38 En fUS, Revista de Derecho y Ciencias Sociales, T.VIII, n 47, junio, 1942, México, pp. 351-385.

39 Buenos Aires, Losada, 1944.

40 Carlos Cossio, La plenitud del ordenamiento jurídico, cit., pp. 92-93. 
pia", pese a reconocer que ha sido capaz de ofrecer una definición positiva. Antes de proseguir en su crítica, el profesor argentino entiende que son necesarias ciertas precisiones terminológicas, debido a que Máynez usa como sinónimas las expresiones derecho de libertad y libertad jurídica, ${ }^{41}$ algo que no le parece apropiado. Para Cossio, el "derecho de libertad" es lo que él denomina "derecho o facultad de señorío", y "la libertad jurídica", es la libertad en sentido metafísico, jurídicamente considerada y calificada como lícita.

Tal como señalamos anteriormente el punto de partida de los análisis de Máynez, estaba en la clasificación tradicional entre actos ordenados, prohibidos y permitidos; pues bien, para Cossio, esto es un error. En primer lugar, porque dicha clasificación es considerada lógicamente falsa, dado que carece de principium divisionis; ${ }^{42}$ y en segundo lugar, porque es innecesaria, y plantea la duda de si el Prof. mexicano la sigue (en su perjuicio) o la abandona. La abandona - en opinión de Cossio - cuando afirma que el derecho de libertad no es una especie situada en el mismo plano que el resto en la clasificación de los derechos subjetivos, sino una forma categorial de manifestación de todo derecho subjetivo. ${ }^{43} \mathrm{Y}$ se mueve dentro del esquema, cuando distingue lo permitido en lato sensu y stricto sensu, y en el ámbito de este último (lo lícito potestativo) encasilla el

41 La plenitud del ordenamiento jurídico, cit., p. 94, donde dice: "No nos parece que se puedan usar como sinónimas las expresiones derecho de libertad y libertad jurídica, pus en tanto la primera es unívoca al referirse a la facultad de señorío, la segunda es equívoca porque, junto con esta sinonimia artificialmente establecida, conserva siempre su referencia a otra diversa cual es el dato metafísico de la libertad humana jurídicamente considerada y calificada con el signo positivo de lo lícito o permitido".

42 Ibídem, pp. 95-98 y añade: "bajo la enunciación aparente de tres clases de actos o acciones, se refiere en realidad a unos exclusivamente como deberes (secciones 1 y 2 , ordenados y prohibidos) y a otros exclusivamente como facultades (sección 3, permitidos). La división no es, pues, una división lógica; apenas es un agrupamiento de actos”. Y unos párrafos después dice: “...la facultad jurídica está en los tres casilleros...".

43 Ibídem, p. 99. 
derecho de libertad. Distinción entre lo lícito potestativo y lo lícito obligatorio, que según Cossio, es lógicamente falsa dos veces. Una, porque el concepto de lícito obligatorio, no hace referencia a la facultad o derecho del obligado. Otra, porque la licitud es una nota puramente lógica del Derecho, que como tal no puede ser determinada como potestativa ni como obligatoria. ${ }^{44}$

Después de las anteriores observaciones, Cossio se reafirma en la crítica a la postura de Máynez de entender sinónimas las expresiones "libertad jurídica" o "libertad como derecho" y "derecho de libertad". Para Cossio, denominar derecho de libertad a la "facultad de señorío" no plantea mayores problemas; pero dejar la libertad jurídica limitada a eso, "es algo que no se puede aceptar sin gran violencia de los términos y sus significaciones, porque al ejercitar mi derecho de cumplir mi propia obligación, mi libertad metafísica de hacerlo es libertad como derecho, aunque no es facultad jurídica de señorío". ${ }^{45}$ Como muestra del error en que se incurre al limitar la libertad jurídica al ámbito de los procederes potestativos, se señala el distinto modo que tiene Máynez de justificar los derechos subjetivos. Según Cossio, emplea dos criterios de diverso valor lógico: para la facultad de señorío, la vía demostrativa y para la facultad de inordinación o derecho del obligado (en terminología de Máynez) la vía mostrativa. Mientras este segundo es de fácil justificación, pues quien tiene el deber de hacer algo, esta lógicamente autorizado para hacerlo (es el juego del principio de no contradicción); la facultad de señorío no tiene otra justificación -para Máynez- que el camino de la vía demostrativa, y se recurre a una demostración teleológica. ${ }^{46}$ Cossio, por su parte, entiende "que la facultad de se-

${ }^{44}$ Ibídem, p. 100, y continua: "lo lícito en cuanto tal es idéntico en uno y otro caso y su concepto no se enriquece o determina mayormente con agregarle los calificativos de potestativo u obligatorio, que no se refieren a él, ciertamente, sino a la actividad que ejercita el sujeto jurídico"

${ }^{45}$ Ibídem, p. 101.

46 Ibídem, pp. 103-106. 
ñorío se justifica lo mismo que la facultad de cumplir con el propio deber, es decir por mostración y no por demostración”. Mostración que es la misma en ambos casos, "porque en ambos casos lo que se muestra con evidencia inmediata es el Derecho en tanto facultad". ${ }^{47}$

Máynez responde a las anteriores críticas, de manera extensa y pormenorizada, en su artículo: "Una discusión sobre el concepto jurídico de libertad (Respuesta a Carlos Cossio)". Ya podemos adelantar, que Máynez se reafirma en sus tesis centrales y entiende que la mayor discrepancia entre ambos es puramente terminológica y de cuestiones de importancia secundaria en amplia medida fruto de problemas interpretativos.

$\mathrm{Al}$ igual que en su momento hiciera Cossio, Máynez comienza su respuesta realizando las precisiones terminológicas necesarias para situar y comprender las posiciones adoptadas. Y no cree que la respuesta que da al interrogante ¿qué es la libertad jurídica? pueda ser tachada de "impropia" por el hecho de emplear la expresión "libertad jurídica" como sinónimo de "derecho de libertad", pues para Máynez ambas expresiones poseen un significado unívoco. Para él, la libertad en el ámbito jurídico "sólo puede ser correctamente concebida como derecho". Cuestión distinta es la libertad de la voluntad, que "puede ser considerada como dato de cualquier facultad jurídica (no sólo del derecho de libertad), en cuanto es un hecho que el derecho no ha creado, sino que existe independientemente de él, como algo «dado» al mismo". ${ }^{48}$ Para Máynez, lo indebido no es el llamar "libertad jurídica" al "derecho de libertad", sino el de-

47 Ibídem, p. 107, y en la siguiente página añade: “... lo que necesita justificación son las limitaciones a la facultad de señorío; y esa justificación, que es contingente, es axiológica...". Y en las páginas 109-114, aparte de otras consideraciones marginales, nos indica que la facultad jurídica se justifica ontológicamente en el principio evidente de que todo lo que no está prohibido está jurídicamente permitido. Lo cual es válido tanto para la facultad de señorío como para la de cumplir con el propio deber, o en palabras de Cossio, "facultad de inordinación".

48 Ver, "Una discusión sobre el concepto jurídico de libertad" (Respuesta a Carlos Cossio), cit., p. 351. 
nominar "libertad jurídica" a la "libertad de la voluntad", porque esta no es derecho, sino hecho. De ahí que no se deban confundir, ni identificar la libertad como derecho y la libertad como dato o como voluntad. Y prueba de ello es el propio título de su trabajo: "Libertad como derecho y como poder", que revela el propósito de distinguir ambos conceptos. Aunque la libertad de la voluntad presente el signo de lo lícito o lo permitido tanto en el caso del derecho de libertad como en el de cumplir la propia obligación, entre ambos existe una diferencia esencial, que obedece a la no identidad de tales derechos. Para apreciar mejor la distinción entre dichos derechos, nos presenta el siguiente esquema (casi innecesario por su simplicidad):

\begin{tabular}{|l|l|l|}
\cline { 2 - 3 } \multicolumn{1}{l|}{} & EJERCicio & No EJERCicio \\
\hline $\begin{array}{l}\text { Derechos cuyo contenido no se } \\
\text { reduce a la facultad de cumplir un } \\
\text { deber propio. }\end{array}$ & permitido & permitido \\
\hline $\begin{array}{l}\text { Derecho al cumplimiento de la } \\
\text { propia obligación.* }\end{array}$ & permitido & prohibido \\
\hline $\begin{array}{l}\text { * “Una discusión sobre el concepto jurídico de libertad" (Respuesta a Carlos } \\
\text { Cossio), cit., pp. 354-356. }\end{array}$ & \\
\hline
\end{tabular}

Desde el punto de vista terminológico, a Máynez le resulta indebido el crear la denominación "derecho de señorío" para un derecho que siempre se ha llamado de libertad, así como denominar jurídica a la libertad del querer, de la voluntad o libertad metafísica. ${ }^{49}$

Por otro lado, respecto a la crítica del esquema de clasificación tradicional de los actos humanos desde el punto de vista jurídico en: ordenados, prohibidos y permitidos, Máynez considera que "no

49 Cfr., Ibídem, p. 357. 
puede considerarse como lógicamente falso porque, en primer lugar, si tiene principium divisonis y, en segundo término, porque el «agrupamiento» a que alude Cossio es completo, ya que todo acto humano corresponde jurídicamente a cualquiera de las tres categorías de lo ordenado, lo permitido y lo prohibido". ${ }^{50}$ El principium divisionis, según Máynez, se encuentra implícito en el esquema, y muestra de ello son las propias palabras de Cossio cuando dice que los ordenados y los prohibidos son obligatorios. Dicha división responde a que las obligaciones pueden tener como contenido una acción o una omisión. En cuanto a la crítica de la indecisión de seguir dicho esquema, Máynez considera que no hay tal, y que en realidad no se aparta de dicho esquema cuando afirma que el derecho de libertad no es una especie al lado de otras, sino una forma categorial de manifestación que se refiere exclusivamente a los derechos de primer grado. Y en cambio, cuando se le critica el que siga dicho esquema, las razones que se alegan es que divide lo permitido en lato sensu y stricto sensu y que encasilla el derecho de libertad en este segundo ámbito. Cuando es precisamente lo que pretende demostrar el Prof. mexicano, que la libertad como derecho es una forma categorial de manifestación de las facultades que pertenecen al ámbito de lo permitido stricto sensu o si se prefiere al de lo potestativo. ${ }^{51}$ Tampoco comprende Máynez la crítica de considerar lógicamente falsa la distinción: lícito potestativo y lícito obligatorio. Pues "aun cuando la licitud sea nota puramente lógica del derecho, nada impide distinguir aquello que siendo permitido se agota en la facultad de cumplir un deber propio, de lo que, siendo igualmente lícito, no implica la observancia de un deber propio". 52

50 Ibídem, pp. 360-361.

51 Cfr., ibídem, pp. 365-366, y añade: "Nunca he escrito ni pensado que la libertad jurídica exista en relación con los actos ordenados".

52 Ibídem, p. 368, distinción que Máynez considera clave para la noción de la libertad como derecho. 
Frente a la objeción de que Máynez justifica el derecho subjetivo mediante una demostración teleológica; éste responde que más que una justificación teleológica, es normativa, porque no se basa en los conceptos de medio y fin, sino en la noción de deber. Y añade: "lo que en última instancia justifica mi derecho de libertad, es el deber jurídico a que se halla mediata o inmediatamente referido, no la circunstancia de que se manifieste en la selección de los medios que condicionan el cumplimiento de tal deber". ${ }^{53}$ En apoyo de su tesis, Máynez menciona una obra por la que siente especial admiración: El sentido funcional del derecho de propiedad, de M. Semprún y Gurrea, ${ }^{54}$ por considerarla el estudio más profundo que conoce de justificación del derecho subjetivo como función del deber jurídico. Como muestra de que el derecho y el deber se encuentran indestructiblemente ligados, se destacan las siguientes afirmaciones de Semprún y Gurrea: "No hay ningún derecho que conceptualmente no se engendre en un deber", afirmación que se completa con ésta otra: "De todo deber se deduce lógicamente un derecho". ${ }^{55}$ Ideas que le sirven a nuestro autor para afirmar que, si bien el principio que usa Cossio de que "todo lo que no está prohibido está permitido", resulta evidente y es una mostración, no es realmente una justificación. Para justificar en el ámbito normativo hay que demostrar no que algo existe, sino que debe existir. Lo que en palabras de Máynez sería: “...para justificar un derecho (ya se reduzca a la facultad de cumplir un deber propio, o sea derecho al cumplimiento de un deber ajeno) es indispensable mostrar, en la forma en que lo hace Semprún y hemos tratado de

53 Ibídem, p. 373, y sigue: "Pues una cosa es el contenido del derecho de libertad y otra muy distinta la justificación del mismo en función de ciertos deberes del sujeto".

54 Edit. Revista de Derecho Privado, Madrid, 1933.

55 Cfr., "Una discusión sobre el concepto...", cit. pp. 374-376. 
hacerlo nosotros, la relación genética existente entre lo debido y lo permitido". ${ }^{56}$

Por último, Máynez se reafirma en su tesis central de distinción entre el derecho de libertad y la libertad metafísica, sin desconocer que ésta es un "dato" frente cualquier facultad jurídica. Desde el punto de vista terminológico le parece un uso más correcto el que él hace de la libertad jurídica y no el de Cossio que denomina jurídica a la libertad metafísica o de la voluntad. Y como apoyo de dicha distinción entre ambos tipos de libertad, la jurídica y la de la voluntad, Máynez hace referencia a la posición que mantiene N. Hartmann, ${ }^{57}$ para quien "la libertad jurídica no implica un poder (können) sino un estar facultado o autorizado (dürfen). Su radio de acción no es el de lo elegible, sino el de lo permitido, es decir, el de aquello a lo que la persona está legalmente autorizada". "La libertad de la voluntad es libertad del poder hacer, no del estar facultado". ${ }^{58}$ Resulta evidente que la libertad jurídica y la libertad de la voluntad son dos cuestiones diversas en esa relación entre poder y facultad.

\section{BALANCE}

A modo de balance o síntesis de lo más significativo de la anterior discusión entre Cossio y Máynez, podemos apuntar lo siguiente:

En primer lugar, son más los elementos de coincidencia que de discrepancia entre ambas posiciones, máxime teniendo en cuenta la

56 Ibídem, p 382, y sigue: "De lo contrario simplemente se muestra que se permite lo que no se prohíbe, mas no que necesariamente ciertas formas de conducta deban permitirse. Además, la oposición contradictoria de los términos prohibido-permitido no puede ser considerada como una justificación del derecho de libertad porque, como hemos visto más arriba, la palabra permitido se emplea aquí en su sentido amplio y se refiere, en consecuencia, tanto al derecho del obligado, cuanto al derecho de libertad".

57 Nicolai Hartmann, EthiK, Berlín, Zweite Aufl, 1935, en especial pp. 580-581.

58 Ver, Una discusión sobre...", cit., p. 385. 
diversa concepción filosófica del derecho que mantiene uno y otro autor. A modo de ejemplo de lo dicho, véase la siguiente crítica que dirige el Prof. mexicano a Cossio: "Estoy de acuerdo en que la conducta es «libertad metafísica fenomenalizada» (yo preferiría decir: manifestación de la libertad metafísica); pero no considero correcto afirmar que el Derecho es conducta. El derecho es norma de conducta, no conducta". ${ }^{59}$ Como se ve, existe más diferencia entre ambos sobre qué sea el derecho, qué sobre lo que sea la libertad jurídica.

En segundo lugar, la mayor parte de la discusión se ha centrado en cuestiones terminológicas, esto es, en diferencias de denominación entre ambos autores. Si bien es cierto que en aras del rigor y el entendimiento es necesario realizar un esfuerzo de precisión terminológica, no es menos cierto que las cuestiones nominativas son un primer paso o nivel de análisis que una vez realizado requiere pasar al nivel sustancial o de contenidos de los problemas planteados. De hecho, una vez aclaradas las anteriores cuestiones de denominación, la diferencia más significativa es la mayor extensión que el Prof. argentino le atribuye a la libertad jurídica. Mientras Máynez limita la libertad jurídica al campo de lo potestativo, Cossio entiende que se da en todo el campo de lo lícito, tanto en el ejercicio de los derechos independientes como en los dependientes, facultades de inordinación o si se prefiere derechos del obligado.

En tercer lugar, reconociendo en general que son más los acuerdos que las diferencias entre ambas posiciones, en las matizaciones y apreciaciones concretas de las cuestiones estamos más de acuerdo con las razones y explicaciones aducidas por Máynez, con las siguientes precisiones o salvedades:

$1^{\mathrm{a}}$.- El esquema tradicional de división de los actos humanos regulados por el derecho en tres sectores, no nos parece necesario para llegar a la definición positiva de la libertad jurídica dada por García Máynez. Desde el punto de vista lógico es necesaria y suficiente la

59 Ib., p. 370. 
división que establece los procederes regulados por el derecho, en conductas de ejecución potestativa y de ejecución no potestativa. Quedando la libertad jurídica referida al primer ámbito. Otra cosa es que el segundo, el de los procederes no potestativos, lo dividamos en jurídicamente ordenados y jurídicamente prohibidos, lo que para el derecho de libertad no tiene repercusión alguna.

$2^{a}$.- Cuando Máynez se pregunta qué ¿por qué da Cossio el calificativo de jurídica a la libertad como dato o metafísica referida al Derecho?; ${ }^{60}$ pensamos que la respuesta está implícita en la misma pregunta, y no resulta en modo alguno desafortunada ni indebida. Cossio la denomina libertad jurídica, porque hace referencia a la conducta humana que puede ser considerada y calificada jurídicamente como lícita. No nos parece que exista ningún inconveniente en aceptar que se puede hablar de la "libertad jurídica" en relación a actos lícitos, al lado del "derecho de libertad" y de la libertad en general o libertad de la voluntad. Son tres expresiones distintas con contenidos diversos y distinta extensión; lo que ocurre es que debido al empleo que hace Máynez de dichas expresiones, en concreto considerando como sinónimas la "libertad jurídica", el "derecho de libertad" y la "libertad como derecho", no admite ese tercer ámbito de lo que Cossio llama la libertad jurídica, referida a todo proceder lícito.

$3^{\text {a }}$.- Señalar, por último, que las citas de N. Hartmann realizadas por Máynez, ${ }^{61}$ son claras en cuanto a la diferencia entre libertad jurídica y libertad de la voluntad. Lo que no está claro, es el ámbito de la libertad jurídica. Ámbito que se enmarca dentro de lo permitido. Pero ¿de qué permisión se habla?, si es en sentido lato, está más próxima al sentir de Cossio, que al del propio Máynez que trae la cita a colación.
60 Ib., p. 384.
61 Ib., pp. 384-385. 